\title{
PERILAKU KONSUMEN TERHADAP KEPUTUSAN MENGKONSUMSI PRODUK AGROINDUSTRI ABON IKAN LELE ORIGINAL
}

\author{
CONSUMER BEHAVIOUR IN DECISION MAKING \\ TO CONSUME ORIGINAL CATFISH SHREDDED
}

\author{
Ristina Siti Sundari*1 ${ }^{1}$, Dona Setia Umbara ${ }^{1}$, Adnan Arshad ${ }^{2}$ \\ ${ }^{1}$ Universitas Perjuangan, J1. PETA No. 177 Tasikmalaya 46115 \\ ${ }^{2}$ China Agricultural University, Beijing 100193, P.R of China \\ *E-mail: ristina.sitisundari@yahoo.com \\ (Diterima 22-06-2020; Disetujui 23-07-2020)
}

\begin{abstract}
ABSTRAK
Diversifikasi pangan dalam rangka penguatan ketahanan pangan keluarga semakin diprioritaskan terutama dalam masa pendemik COVID-19 terjadi kalangkaan supply chain pangan. Penelitian ini dilakukan untuk mengetahui perilaku konsumen dalam mengonsumsi produk diversifikasi pangan abon ikan lele original dan menganalisis atribut yang paling mempengaruhi dan saran konsumen yang paling dominan. Metode penelitian menggunakan analisis korelasi Rank Spearman pada 100 reponden yang diwawancarai. Hasil penelitian menunjukkan bahwa perilaku konsumen memegang peranan penting dalam pengambilan keputusan mengonsumsi produk agribisnis diversifikasi pangan abon ikan lele. Korelasinya adalah semakin diperhatikan perilaku konsumen dalam pengambilan keputusan ini maka konsumen semakin tinggi memutuskan untuk mengonsumsi abon ikan. Sehingga produk abon ikan dapat didistribusikan dengan baik. Hasil uji organoleptik yang dianalisis dengan uji Rank Spearman memperlihatkan konsumen menyukai abon berbahan baku ikan yang bertekstur lebih halus, berstruktur lembut dan rasanya yang enak. Namun, konsumen ada yang menyarankan untuk menurunkan tingkat keamisannya untuk penelitian produk abon ikan lebih lanjut.
\end{abstract}

Kata kunci: Abon, diversifikasi, ikan lele, perilaku konsumen

ABSTRACT

Food diversification of fish in strengthening livelihood food security is getting priority, particularly during the COVID-19 pandemic. Almost all habits and behavior have changed. The scarcity and distribution gaps of the supply chain occurred, and hopefully, the new normal era will soon come. The research carried out to know the consumer behavior in decision making to consume diversification products of original catfish shredded and analyze the most dominant affected attribute. The research used the Rank Spearman Correlation Test toward interviewed 100 respondents. The result indicated that consumer behavior has an essential role in decision making to consume agribusiness diversification products of catfish shredded. The correlation is the more paying attention, the more consumer decided to consume catfish shredded. The product can distribute well. Analysis of organoleptic concluded that consumers refer to catfish shredded. It has a soft texture, refine the structure, delicious taste, and easy to chew, whereas catfish shredded had odor. Suggestion to advance research to eliminate odor catfish.

Keywords: Shredded, diversification, Catfish, Consumer behavior

PENDAHULUAN

Pandemik Covid-19 merubah

tatanan kehidupan di seluruh dunia.
Perubahan gaya hidup menurut (Yuswohady, Fatahilah, Rachmaniar, \& Hanifah, 2020) terjadi empat perubahan 


\section{PERILAKU KONSUMEN TERHADAP KEPUTUSAN MENGKONSUMSI \\ PRODUK AGROINDUSTRI ABON IKAN LELE ORIGINAL \\ Ristina Siti Sundari ${ }^{* 1}$, Dona Setia Umbara ${ }^{1}$, Adnan Arshad}

besar (Consumer Behavior Megashift), yaitu gaya hidup tinggal di rumah (Stay at home lifestyle), kembali ke piramid dasar (back to the bottom pyramid), serba virtual (go virtual), dan masyarakat yang memiliki rasa empati (empathic society). Perilaku masyarakat berubah, perilaku mengonsumsi produk pangan juga berubah. Diversifikasi pangan semakin disadari pentingnya dalam kondisi seperti ini. Hal ini lebih menegaskan pentingnya pemberdayaan masyarakat dalam mengolah bahan pangan terutama ikan (Azis, Safitri, Irmawati, \& Suparmin, 2019) yang banyak terdapat di Jawa Barat agar memberikan nilai tambah dan mutunya terjaga.

Upaya mempertahankan mutu ikan dengan cara penanganan yang tepat agar ikan tetap sempurna atau dengan cara mengawetkan dan mengolahnya sehingga secara ekonomis nilai tambah produk juga meningkat. Ikan lele saat ini banyak dibudidayakan di perkotaan sebagai produk pertanian perkotaan akuaponik bersamaan dengan tanaman sayuran seperti kangkung, selada dan lain-lain (Kadhafii, Windarti, \& Setiawan, 2016; Pamuji \& Al-Baihaqi, Mohammad Shofi Kinasih, 2014; Sagita, 2014). Ikan lele dalam proses pengawetan untuk konsumsi bisa dibuat menjadi nugget, otak-otak, fillet abon dan lain lain dan bisa dijual dalam bentuk beku (frozen) yang di masa pandemic Covid-19 menjadi primadona bisnis pangan virtual.

Masalah ikan yang dihadapi adalah dalam bentuk segar tdak dapat bertahan lama di tempat terbuka, cepat membusuk dan kondisi ini sangat menurunkan kualitas ikan. Dengan demikian, diperlukan upaya-upaya agar dapat mempertahankan kualitas dan ikan dapat tetap dikonsumsi. Bahkan dengan pengawetan dan pengolahan yang inovatif sehingga secara ekonomis memberikan nilai tambah. Kegiatan pengolahan pasca panen atau agroidustri sangat diperlukan agar memberikan nilai tambah (Ristina Siti Sundari, Kusmayadi, \& Umbara, 2017). Dengan adanya nilai tambah menjadikan harga jual juga lebih tinggi maka pendapatan dan kesejahteraan petani meningkat. Nilai tambah produk pertanian dapat ditingkatkan dengan melakukan pengolahan yang optimal pada setiap tahapan proses produksi dan pemanfaatan hasil samping yang didukung oleh tren kembali ke alam (Nuzuliyah, 2018; Syaputra, Lubis, \& Iskandarini, 2014) dan meminimalkan limbah dalam rangka menjaga kesehatan di masa pandemik Covid-19 ini.

Abon ikan merupakan salah satu bentuk olahan yang memberikan nilai 
tambah bagi pengelolanya dan dapat meningkatkan kesejahteraan masyarakat (Ristina Siti Sundari, Kusmayadi, \& Umbara, 2017). Dilihat dari sisi preferensi konsumen, abon ikan memiliki level referensi yang tinggi dalam atribut rasa, struktur dan tekstur karena lebih mudah dicerna dibanding dengan abon hewan yang lain (R.S. Sundari, Umbara, Fitriadi, \& Sulaeman, 2019). Produk yang dihasilkan mempunyai bentuk lembut, rasa enak dan memiliki keawetan yang tinggi bahkan bisa mencapai lebih dari tujuh bulan. Abon ikan merupakan produk hasil olahan yang dibuat dari daging ikan, yang dikombinasikan dengan proses penggilingan, penggorengan (Azis et al., 2019; Ismail \& Putra, 2017). Peralatan yang dibutuhkan untuk pembuatan abon bisa sederhana dan manual, bisa modern dengan dibantu peralatan mekanis sehingga untuk memulai usaha ini relatif tidak memerlukan biaya investasi yang besar. Dengan demikian, usaha pengolahan ikan menjadi abon bisa dilakukan mulai dari skala usaha kecil. Hal ini membuat usaha ini sangat berpotensi untuk dikembangkan di banyak wilayah di Indonesia yang memiliki sumberdaya perikanan.
Ikan lele di Tasikmalaya sudah banyak dibudidayakan. Melalui pengolahan abon ikan dapat memberikan nilai tambah untuk kesejahteraan masyarakat. Hal ini mengindikasikan bahwa usaha pengolahan abon ikan mempunyai prospek yang baik sehingga dapat diandalkan dalam memajukan perekonomian masyarakat. Produk abon ikan lele memiliki nilai konversi 0,35 (Sundari, dkk 2016). Harga ikan segar Rp 20.000 - Rp. 28.000 tiap kilogram sedangkan setelah diolah menjadi abon harganya $\mathrm{Rp}$ 190.000-240.000 tiap kilogramnya.

Salah satu pelaku penting dalam perekonomian yaitu konsumen yang mengonsumsi suatu produk. Menurut Hermawan (2012), karakter konsumen yang mencakup sikap dan perilaku bukanlah sesuatu yang tetap atau statis namun konsumen berkembang dan berubah, dinamis. Konsumen akan mempunyai persepsi yang baru, memori baru dan pengalaman yang baru dalam kehidupan mereka sebagai konsumen. Saat ini diduga perilaku konsumen mulai bergeser dari mengkonsumsi abon sapi ke abon ikan yang harganya lebih murah namun bergizi tinggi. Dengan demikian, ingin diketahui perilaku konsumen dalam 


\section{PERILAKU KONSUMEN TERHADAP KEPUTUSAN MENGKONSUMSI \\ PRODUK AGROINDUSTRI ABON IKAN LELE ORIGINAL \\ Ristina Siti Sundari*1, Dona Setia Umbara ${ }^{1}$, Adnan Arshad}

pengambilan keputusan membeli produk abon ikan.

\section{METODE PENELITIAN}

Penelitian ini menggunakan metode survey kepada 100 responden dari berbagai lapisan masyarakat. Selanjutnya responden menjawab kuesioner yang peneliti tanyakan. Tahapan penelitian yang dilakukan mulai dari survey pendahuluan, identifikasi variabel, penyusunan kuesioner, pelaksanaan penelitian, pengumpulan data sampel penelitian, uji dan analisis sampel. Data penelitian berasal dari data primer, yaitu data yang diperoleh langsung dari hasil interview terhadap calon pembeli abon ikan dan data sekunder yang diperoleh dari hasil studi pustaka, jurnal penelitian, bahan publikasi dan dinas terkait yang ada hubungannya dengan penelitian ini baik secar online maupun offline (Sundari, Kusmayadi, Umbara., 2017)

Teknik penentuan responden dilakukan secara sengaja (purposive judgement sampling) yang diambil dari masyarakat di dalam dan lingkungan Universitas Perjuangan. Santoso (2010) dan Riady (2015) menjelaskan bahwa jumlah sampel yang dianjurkan pada penelitian Rank Spearman adalah antara 50 sampel 100 sampel. Sugiyono (2011) menyatakan penelitian Rank Spearman merupakan penelitian korelasi karena adanya hubungan antar variabel di dalamnya. Kemudian dilakukan kombinasi stimuli untuk mendapatkan penilaian responden sebagai konsumen terhadap kombinasi atribut yang terbaik berdasarkan preferensi konsumen.

Variabel yang digunakan pada penelitian ini berupa atribut produk. Atribut produk terdiri atas unsur-unsur produk yang dianggap penting oleh konsumen sehingga dijadikan dasar dalam pengambilan keputusan mengonsumsi (Kotler dan Keller, 2008). Operasionalisasi variabel yang diidentifikasi menjadi atribut sebagai berikut:

1. Konsumen adalah seseorang yang membeli abon ikan untuk dikonsumsi sendiri sebagai konsumen akhir.

2. Perilaku konsumen adalah kegiatankegiatan konsumen yang secara langsung terlibat dalam membuat keputusan pembelian, menggunakan dan mengatur pembelian abon ikan.

3. Abon ikan adalah produk abon berbahan baku ikan lele segar.

4. Produsen adalah yang menjual abon ikan lele.

5. Variabel adalah unsur-unsur pada produk, harga, promosi, tempat yang 
dipertimbangkan konsumen dalam keputusan membeli abon ikan. Dalam hal ini adalah: kesan kualitas, cita rasa, kemasan dan proses produksi, persepsi konsumen terhadap penawaran harga, tingkat harga abon ikan lele, perbandingan harga dengan kualitas, anggapan standar harga abon, jarak, kenyamanan, pelayanan, kebersihan, keamanan, hadiah, dukungan sponsor, kesan terhadap iklan.

a) Kualitas produk: ukuran relatif abon ikan terhadap keunggulan suatu produk untuk memenuhi selera konsumen. Kualitas produk dicerminkan melalui cita rasa, mutu, proses produksi dan kemasan.

b) Harga: besarnya uang yang diperlukan untuk mendapatkan kombinasi antara produk abon ikan lele dan pelayanan yang menyertainya.

c) Tempat: ukuran rentang antara konsumen dan produsen. Dicerminkan dengan indicator jarak, kenyamanan, pelayanan, kebersihan, keamanan.

d) Promosi: upaya yang dilakukan produsen untuk menyampaikan informasi, mempengaruhi dan menstimulasi konsumen tentang produk yang dihasilkan.

6. Variabel Keputusan Konsumen: adalah keputusan yang diambil oleh konsumen untuk melakukan pembelian produk abon ikan. Variabel ini diukur berdasarkan motivasi konsumen untuk membeli dengan atribut sebagai berikut:

a) Individu: konsumen, motivasi, pengetahuan, keterlibatan, sikap, demografi, kepribadian, gaya hidup.

b) Lingkungan: kelas sosial, budaya, situasi, pengaruh pribadi, keluarga.

c) Proses psikologis: proses pengolahan informasi, proses perubahan sikap, dan pembelajaran,

Pembentukan variabel penelitian dilakukan dengan mengkombinasi level atribut menjadi sebuah stimuli atau profil yang terbentuk dalam melaksanakan analisis korelasi Rank Spearman. Kombinasi variabel diberikan untuk mendapatkan penilaian responden terhadap kombinasi atribut yang paling baik menurut perilaku konsumen. Penilaian dilakukan dengan skala likert seperti terlihat pada Tabel 1 . 
Tabel 1. Skala Likert Kuesioner

Tidak suka 1

Setelah angket dikumpulkan dari responden yang menyangkut perilaku konsumen dalam mengkonsumsi abon ikan lele, langkah selanjutnya ditabulasi dan dianalisis. Kuesioner yang dibuat menggunakan Skala Likert dengan pembobotan melalui skor 5-4-3-2-1.

Rumus yang digunakan untuk melakukan analisis data, yakni Nilai Tertimbang (Djoni, 2008) adalah:

$$
\mathrm{NT}=\frac{\text { Nilai yang dicapai }}{\text { Nilai Ideal }(\text { maksimum })} \text { X } 100 \text { persen }
$$

Penentuan interval kelas untuk indikator dari variabel perilaku konsumen dan keputusan mengkonsumsi abon ikan formulasinya sebagai berikut:

$$
\text { Klasifikasi }=\frac{\text { Skor Maksimal }- \text { Skor Minimal }}{\text { Jumlah Kategori }}
$$

Metode pengujian Rank Spearman dilakukan untuk mengetahui ada atau tidaknya hubungan antara 2 variabel yang dihipoteisis (Riyadi, 2015).

1) Jika terdapat sedikit rank kembar/tidak sama sekali, dengan rumus:

Keterangan :

$$
\mathrm{r}_{\mathrm{s}}=1-\frac{6 \sum_{\mathrm{i} 1}^{\mathrm{N}} \mathrm{di}}{\mathrm{N}^{3}-\mathrm{N}}
$$

$\mathrm{r}_{\mathrm{s}}=$ Korelasi Rank Spearman

$\sum \mathrm{di}^{2}=$ Perbedaan antara jarak rank $\mathrm{X}$ dan rank $\mathrm{Y}$

$\mathrm{N}$ = Jumlah responden
2) Jika terdapat banyak rank kembar dari variabel tersebut, maka mengatasinya dengan diberi rank rata-rata. Cara menghitung korelasi bila terjadi rank kembar adalah:

$$
\mathrm{r}_{\mathrm{s}}=\frac{\sum x^{2}+\sum y^{2}-\sum d i^{2}}{2 \sqrt{\sum x^{2} \cdot \sum y^{2}}}
$$

Keterangan :

$$
\begin{array}{rlr}
\Sigma \mathrm{x}^{2}= & \text { Nilai dari perilaku } \\
& \text { konsumen } \\
\Sigma \mathrm{y}^{2}= & \text { Nilai dari keputusan } \\
& \text { mengkonsumsi abon } \\
& \text { ikan lele }
\end{array}
$$

Nilai $\sum x^{2}+\Sigma y^{2}$ diperoleh dengan menggunakan rumus sebagai berikut:

$\sum x^{2}=\frac{N^{3}-N}{12-\Sigma \mathrm{Tx}} \longrightarrow \mathrm{Tx}=\frac{t^{3}-t}{12}$
$\sum y^{2}=\frac{N^{3}-N}{12-\Sigma \mathrm{Ty}} \longrightarrow \mathrm{Ty}=\frac{t^{3}-t}{12}$

Keterangan :

$\mathrm{T}=$ Faktor koreksi

$\mathrm{t}=$ Banyaknya kembar data

di $=$ Perbedaan antara $\operatorname{rank} \mathrm{X}$ dan $\mathrm{Y}$

Interpretasi ukuran Korelasi menurut Sugiyono (2011):

\begin{tabular}{ccccc}
\hline $0.00-$ & $0.21-$ & $0.41-$ & $0.61-$ & $0.81-$ \\
0.20 & 0.40 & 0.60 & 0.80 & 1.00 \\
\hline $\begin{array}{c}\text { Tidak } \\
\text { ada }\end{array}$ & rendah & sedang & tinggi & sempurna \\
\hline
\end{tabular}

\section{Menentukan hipotesis}

Untuk penentuan signifikansi $r_{s}$ diuji dengan:

$$
\mathrm{t}_{\text {hit }}=\operatorname{Rs} \sqrt{\frac{\mathrm{n}-2}{1-(\mathrm{rs})^{2}}}
$$

Kriteria uji yang digunakan untuk menetapkan keputusan hipotesis adalah: 
Jika $t_{\text {hitung }} \geq t_{\text {tabel }} \longrightarrow$ tolak hipotesis nol/terima $\mathrm{H}_{1}$

Jika $t_{\text {hitung }}<\mathrm{t}_{\text {tabel }} \rightarrow$ terima hipotesis nol/tolak $\mathrm{H}_{1}$

Selanjutnya hasil uji ini $\left(t_{\text {hit }}\right)$ akan dibandingkan dengan $\delta b=n-2$ dengan hipotesis sebagai berikut:

$\mathrm{H}_{\mathrm{o}}: \mathrm{p} \leq 0$ : Tidak terdapat hubungan negatif antara perilaku konsumen dengan keputusan mengkonsumsi abon ikan lele $\mathrm{H}_{1}: \mathrm{p}>0: \quad$ Terdapat hubungan positif antara antara perilaku konsumen dengan keputusan mengkonsumsi abon ikan lele

\section{HASIL DAN PEMBAHASAN}

Hasil analisis nilai tertimbang tiap indikator perilaku dapat dilihat pada Tabel 2.

Tabel 2. Analisis Perilaku Konsumen Abon Ikan

\begin{tabular}{llcccc}
\hline \multicolumn{1}{c}{ No. $\quad$ Indikator } & $\begin{array}{c}\text { Nilai } \\
\text { Ideal }\end{array}$ & $\begin{array}{c}\text { Nilai } \\
\text { yang } \\
\text { didapat }\end{array}$ & $\begin{array}{c}\text { NT } \\
\mathbf{( \% )}\end{array}$ & $\begin{array}{c}\text { Kate- } \\
\text { gori }\end{array}$ \\
\hline $1 \quad \begin{array}{l}\text { Kualitas } \\
\text { Produk }\end{array}$ & 20 & 13,32 & 67 & Tinggi \\
2 & $\begin{array}{l}\text { Harga } \\
3\end{array}$ & 10 & 7,77 & 78 & Murah \\
$4 \quad$ Kepraktisan & 10 & 7,68 & 77 & Tinggi \\
Aroma & 5 & 2,67 & 53 & Sedang \\
\hline $\begin{array}{l}\text { Nilai } \\
\text { Indikator total }\end{array}$ & 45 & 31.57 & 70 & Tinggi \\
\hline
\end{tabular}

Sumber: data diolah (2020)

Dalam memutuskan mengonsumsi produk abon ikan konsumen memperhatikan kualitas produk yang tinggi, lebih praktis tetapi harganya murah dengan nilai tertimbang berturutturut $67 \%, 77 \%$ dan $67 \%$. Kualitas ini meliputi gizi, kebersihan dan kemurnian abon. Namun, konsumen masih ada yang menilai bahwa aroma amisnya khas dan masuk kategori sedang dengan nilai tertimbang 53\%. Konsumen meminta abon ikan yang aroma amisnya bisa diminimalkan. Akan tetapi, ada yang menyukai khas aroma ikan. Nilai seluruh indikator dalam kategori yang tinggi dengan NT 70\%. Harga abon ikan termasuk murah namun produk ini belum akrab dalam keseharian konsumen, masih merupakan produk baru. Namun dari harga lebih cenderung memilih abon ikan karena lebih murah dibandingkan abon sapi (Sundari dkk., 2018). Di samping itu, perlu dipertimbangkan mengenai kebijakan penentuan hara, lokasi, produk, promosi, pelayanan (Elisabeth, 2017) agar lebih memberi kepuasan.

\section{Analisis Pengambilan Keputusan dalam Mengonsumsi Abon Ikan}

Tabel 3. Analisis Pengambilan Keputusan dalam Mengonsumsi Abon Ikan

\begin{tabular}{llcccc}
\hline No. & Indikator & $\begin{array}{c}\text { Nilai } \\
\text { Ideal }\end{array}$ & $\begin{array}{c}\text { Nilai } \\
\text { yang } \\
\text { didapat }\end{array}$ & $\begin{array}{c}\text { NT } \\
(\%)\end{array}$ & $\begin{array}{c}\text { Kate- } \\
\text { gori }\end{array}$ \\
\hline 1 & Individu & 15 & 9,12 & 61 & Tinggi \\
2 & Lingkungan & 10 & 7,75 & 78 & Tinggi \\
3 & Proses & 15 & 9,78 & 65 & Tinggi \\
$\quad$ Psikologi & & & & Tinggi \\
\hline Nilai seluruh & 40 & 26,65 & 68 & \\
Indikator \\
\hline
\end{tabular}

Keputusan mengonsumsi abon ikan terutama dilihat dari individunya yang 


\section{PERILAKU KONSUMEN TERHADAP KEPUTUSAN MENGKONSUMSI \\ PRODUK AGROINDUSTRI ABON IKAN LELE ORIGINAL \\ Ristina Siti Sundari*1 ${ }^{*}$, Dona Setia Umbara ${ }^{1}$, Adnan Arshad}

masuk kategori tinggi dengan NT 61\%. Indikator individu ini meliputi pengalaman mengonsumsi, pengetahuan, merek dan keawetan produk. Ternyata faktor merek juga memegang peranan penting bagi konsumen untuk pengambilan keputusan (Supriyono, 2015). Konsumen melihat mereknya dulu sebelum mengambil keputusan. Lingkungan termasuk kategori tinggi dengan NT 78\% dalam mempengaruhi keputusan konsumen memgonsumsi abon ikan. Indikator lingkungan terdiri atas pengaruh dan pendapatan. Proses psikologi meliputi gaya hidup, pembelajaran, budaya, kepercayaan dan cara membeli. Indikator tersebut memiliki kategori tinggi dengan NT 65\%. Hal ini sesuai dengan (Purwitasari, 2015) bahwa keputusan pembelian dipengaruhi secara dominan oleh kepercayaan. Secara keseluruhan indikator mencapai kategori tinggi (NT 67\%).

\section{Analisis Hubungan Perilaku Konsumen dan Pengambilan Keputusan untuk Mengonsumsi Abon Ikan}

Hasil Uji Korelasi Rank Spearman menunjukkan terdapatnya korelasi yang sangat nyata perilaku konsumen dalam proses pengambilan keputusan untuk mengonsumsi produk abon ikan dengan nilai signifikansi sebesar 0,575 . Dengan demikian, semakin tinggi nilai perilaku konsumen terhadap produk abon ikan maka akan semakin tinggi pula proses pengambilan keputusan untuk mengonsumsinya (Tabel 4).

Tabel 4. Hasil Uji Korelasi Perilaku Konsumen dan Pengambilan Keputusan Mengonsumsi Abon Ikan

\begin{tabular}{|c|c|c|c|c|}
\hline & & & $X$ & $\mathrm{Y}$ \\
\hline & & Correlation & 1.000 & $.575^{* *}$ \\
\hline & & Coefficient & & \\
\hline & $\mathrm{X}$ & $\begin{array}{l}\text { Sig. (2- } \\
\text { tailed) }\end{array}$ & . & .000 \\
\hline Spearman's & & $\mathrm{N}$ & 100 & 100 \\
\hline rho & & Correlation & $.575^{* *}$ & 1.00 \\
\hline & & Coefficient & & \\
\hline & Y & $\begin{array}{l}\text { Sig. (2- } \\
\text { tailed) }\end{array}$ & .00 & . \\
\hline & & $\mathrm{N}$ & 100 & 100 \\
\hline $\begin{array}{l}X=\text { Peri } \\
\text { keputusan }\end{array}$ & & konsumen, & $=$ Pen & mbilan \\
\hline
\end{tabular}

\section{KESIMPULAN DAN SARAN}

\section{Kesimpulan}

Perilaku konsumen dalam mengonsumsi abon ikan masuk dalam kategori tinggi dengan nilai tertimbang rata-rata sebesar $70 \%$, namun masih ada masalah aroma bau amis yang ingin diminimalkan atau dihilangkan. Pengambilan keputusan membeli atau mengonsumsi juga termasuk dalam kategori tinggi dengan nilai tertimbang mencapai \%. Pada kedua indikator tersebut terdapat hubungan yang sangat kuat dimana semakin tinggi nilai perilaku konsumen maka semakin tinggi juga 
pengambilan keputusan untuk mengonsumsi produk abon ikan.

\section{Saran}

Perlu dilakukan peneltian lanjutan bagaimana menghilangkan aroma bau amis pada ikan agar abon ikan semakin disukai dan dikonsumsi masyarakat.

\section{UCAPAN TERIMA KASIH}

Ucapan terimakasih yang tak terhingga kepada lembaga Universitas Perjuangan yang telah membantu pendanaan untuk kelancaran penelitian ini.

\section{DAFTAR PUSTAKA}

Azis, A., Safitri, E., Irmawati, \& Suparmin. (2019). Pemberdayaan Masyarakat Berbasis Ketahan Pangan melalui Pengolahan Abon dari Ikan Nila di Desa Pringarata Kecamatan Pringarata Kabupaten Lombok Tengah. Jurnal Warta Desa, 1(1), 75-79.

Elisabeth. (2017). Perbedaan Persepsi Konsumen atas Faktor Penentu Tempat Belanja pada Indomaret dan Alfamart. JRAK, 3(2), 203222.

Hermawan. 2012. Karakter Unik Konsumen. retrieved: https://www.marketing.co.id/10karakter-unik-konsumen-indonesia.

Ismail, A. M., \& Putra, D. E. (2017). Inovasi Pembuatan Abon Ikan Cakalang dengan Penambahan Jantung Pisang. Agritech: Jurnal Fakultas Pertanian Universitas Muhammadiyah Purwokerto, 19(1),
$45-54$.

Kadhafii, A., Windarti, F., \& Setiawan, A. (2016). Akuaponik antipolutan untuk Ruang Khusus Merokok. Surabaya: Universitas Pgri Adi Buana Surabaya Surabaya.

Kotler, P dan Keller, K.L. 2008. Prinsipprinsip pemasaran. Erlangga, Jakara

Nuzuliyah, L. (2018). Analisis Nilai Tambah Produk Olahan Tanaman Rimpang (Added Value Analysis of Rhizome Product). Jurnal Teknologi Dan Manajemen Agroindustri, 7(1), 31-38. https://doi.org/https://doi.org/10.21 776/ub.industria.2018.007.01.4

Pamuji, A. Z. K., \& Al-Baihaqi, Mohammad Shofi Kinasih, I. D. (2014). Akuaponik sebagai jawaban kemandirian pertanian dan perikanan kota surabaya (Vol. 0030). Vol. 0030.

Purwitasari, D. (2015). . Pengaruh Perilaku Konsumen dalam Pengambilan Keputusan Pembelian Produk KFC. Retrieved from http://repository.ub.ac.id/150235/1/ SKRIPSI.pdf

Riady, E. 2015. Statistika dan Aplikasi SPSS. Gramedia. Jakarta.

Sagita, A. (2014). Pengembangan Teknologi Akuakultur BbiofilterAakuaponik ( Integrating Fish And Plant Culture ) sebagai Upaya Mewujudkan Rumah Tangga tahan pangan. Seminar Nasional Tahunan Ke-IV Hasil-Hasil Penelitian Perikanan Dan Kelautan T5 - 25, (December), 353-361. Semarang.

Santoso, S. 2010. Statistika Multivariat. PT Elex Media Komputindo. Jakarta.

Sugiyono. 2011. Metode Penelitian Kuantitatif, Kualitatif dan R\&D. Alfabeta. Bandung.

Sundari, R.S., Umbara, D. S., Fitriadi, B. W., \& Sulaeman, M. (2019). 
Consumer Preference on Catfishes (Patin and Lele) Sweetmeat Product. Journal of Physics: Conference Series, 1179(1). https://doi.org/10.1088/17426596/1179/1/012166

Sundari, R.S., Umbara, D.S., Priyanto, Y.A. 2018. Is Catfish Shredded More Preferable Beef in This Digital Economic Age? Proceeding Internasional. The 2nd International Conference And Call For Paper On Trade "Strategy And Innovation Of Trade In The Digital Economy Age" Jakarta, 5-6 Sep 2018. http://conference.kemendag.go.id/d ownload. Issn 2598-8166

Sundari, Ristina Siti, Kusmayadi, A., \& Umbara, D. S. (2017). Komparasi nilai Tambah Agroindustri Abon Inkan Lele dan Ikan Patin di Tasikmalaya. Jurnal Pertanian
Agros, 19(1), 45-54.

Supriyono, S. (2015). Pengaruh Faktor Budaya, Sosial, Individu dan Psikologi terhadap Keputusan Konsumen Membeli di Indomaret. Kelola, 2(3), 43-60.

Syaputra, E., Lubis, S. N., \& Iskandarini. (2014). Analisis Nilai Tambah Produk Olahan Bolu dan Brownies Rambutan. USU, 1-12. Retrieved from

https://media.neliti.com/media/publ ications/94703-ID-analisis-nilaitambah-produk-olahan-bolu.pdf

Yuswohady, Fatahilah, F., Rachmaniar, A., \& Hanifah, I. (2020). Consumer behaviour new normal after COVID-19. Retrieved from ikbaal23@gmail.com 